\title{
Students' Perceptions and Design Considerations of Flipped Interpreting Classroom
}

\author{
Thi Lan Huynh \\ University of Foreign Language Studies, The University of Danang, Danang, Vietnam \\ Uyen Nu Thuy Nguyen \\ University of Foreign Language Studies, The University of Danang, Danang, Vietnam
}

\begin{abstract}
Digital technologies have become a driver of change that exerts tremendous impact across the disciplines, including education. The Flipped classroom model, carried out in a technology-enhanced environment, has been proven to bring educational innovations. However, in the Vietnamese educational context, the adoption of the flipped model in interpreting courses for undergraduate students has been hardly touched upon in the existing literature. This current study is, therefore, an attempt to examine Englishmajored students' perceptions about this teaching model on Moodle Learning Management Platform and put forward some proposals in the design and implementation of the Flipped Interpreting course. The data were collected using both quantitative and qualitative methods, including a Likert-scale questionnaire and individual interviews. The results revealed that students had positive perceptions toward the adoption of Flipped model and Moodle platform. Analyzing the interconnection of three domains in CoI framework and the additional domain of Technology Use, the authors then offer further recommendations for effective implementation of the model in the EFL classroom context.
\end{abstract}

Index Terms - flipped classroom, moodle learning platform, perception, interpreting course, community of inquiry

\section{INTRODUCTION}

The world has witnessed a host of emerging technological advances in the 21st century. Technology has indeed become a driver of change that exerts tremendous impact across the disciplines, including education. In fact, technology alone is far from enough. It should be well integrated with "intentional and targeted teaching approaches" to better respond to the needs of learners (Fisher, Frey \& Hite, 2016). Moreover, technology can be proven to be transformative in education only when it is employed to have specific problems tackled and genuine innovation generated (Boxser, 2015). The Flipped classroom model, carried out in a technology-enhanced environment, has been evidenced to hold significant potentials for educational innovations which are supposed to be impossible in a traditional classroom.

In order to thrive in such an ever-changing technological landscape, the delivery of knowledge and skills is expected to go beyond the traditional academic teaching. Regarding the local educational setting, the traditional Interpretation Course is characterized by teachers' lectures covering all of the theoretical issues, which is followed by guided practice time. From the researchers' observations, this approach may pose a number of problems. Firstly, struggling students may not yet have sufficient time to digest such fundamental theories before engaging in hands-on activities. Secondly, this approach minimizes the class time for interactive activities. Thirdly, teachers are discouraged from spending more time with individual students, especially in such a big-size class of approximately 40 students. These big concerns have called for the teaching reform in the current Interpretation Course. Therefore, the flipped learning is considered to be a viable solution to the current issues by allowing more activity-based learning rather than information transfer during the face-to-face class meetings, thus pinning hopes on facilitating a more flexible, collaborative and active learning environment. This study aims to investigate third-year students' perceptions of a compulsory Flipped Interpretation course and put forward some implications and recommendations on the design and implementation of flipped courses in the years to come.

\section{LITERATURE REVIEW}

\section{A. Definition of Flipped Classroom}

Flipped classroom is viewed as a unique pedagogical approach, in which the roles of classroom activities and homework are reversed. This learning mode can be divided into three stages: pre-class preparation, in-class activities and post-class consolidation (Kong, 2014). For pre-class stage, students obtain new knowledge at home through online educational materials including instructional videos, podcasts, presentation slides, or other forms of pre-class assignments such as online quizzes, reading worksheets. Learners can be repeatedly exposed to learning resources; i.e., pausing, rewinding, replaying videos and slides as many times needed, which enables them to acquire a deeper 
understanding of the materials. In-class activities are maximized for skills practice when teachers can provide feedback, correction and guidance. Newly - acquired knowledge can then be applied in a richer scope during the onsite session (Bishop \& Verleger, 2013; Garrison \& Vaughan, 2008; Hsieh et al., 2017; Tucker, 2012). During post-class stage, students have opportunities to consolidate their knowledge by reviewing the materials to improve their outcomes.

\section{B. Benefits of Flipped Classroom}

A plethora of studies has showed substantial benefits of flipped classroom across various disciplines. This method has greatly enhanced students' motivation (Strayer, 2012), fostered personalized learning (Hung, 2015), advanced learning engagement and academic performance (Dill, 2012; Mc Laughlin et al., 2014), increased teacher-student and classroom interaction (Hung, 2015), and yielded better learning outcomes (Baepler, Walker, \& Drissen, 2014; Moravec, Williams, Aguilar-Roca, \& O'Dowd, 2010). Other studies have also indicated that flipped learning can promote students' active learning habits (Kim, Kim, Khera, \& Getman, 2014) and develop student-centered learning environments in which students engage actively by making speeches, self-evaluations, collaborate interactively in forms of group discussions and peer evaluations and consequently develop high-order thinking skills such as applying, analysing, creating and evaluating under teacher's guidance and peer support. Additionally, students can apply selfregulated learning for material revision and critical thinking in post-class consolidation (Shea et al., 2012; Zappe et al., 2009).

\section{Theoretical Framework of Flipped Classroom}

Flipped learning consists of two essential components: the involvement of interactive learning activities and the use of computer technologies (Bishop \& Verleger, 2013). Regarding the former component, this research deploys the Community of Inquiry (CoI), which was originally developed by Garrison, Anderson \& Archer (2000) as its analytic framework since blended instructional models, including flipped learning are grounded on social constructivist education principles (Akyol, Garrison, \& Ozden, 2009; Shea \& Bidjerano, 2013). CoI is defined as "a group of individuals involved in a collaborative process of empirical or conceptual inquiries to construct personal meaning and mutual understanding" (Kim, 2017, p.39). This framework postulates three essential elements - teaching, social and cognitive presence - which are considered as "crucial prerequisites for a successful higher educational experience" (Garrison et al., 2000, p.87). Teaching presence (TP) relates to the orchestration of instructional management, building understanding and direct instruction. Social presence (SP) is perceived as students' ability to integrate in the community; i.e. the course of study, collaborate and communicate purposefully in a friendly environment and enhance inter-personal relationships. SP has three underpinning factors - emotional expression, open communication and group cohesion. Cognitive presence (CP) refers to students' capacities to construct and confirm knowledge through connections, collaboration and reflection.

With respect to Technology use (TU) in this study, two broad principles need to be considered (i) ease of use (ii) availability. Specifically, technology should not pose any obstacles to students since the major focus is on promoting their learning experience, not on their skills in using technology. Furthermore, technology should be readily available at the research site such as Moodle E-learning platform in this study since it is unfeasible to purchase or equip new technology for this single course. More importantly, efforts should be made to ensure "regular and systematic use of interactive technology", which makes flipped learning unique and effective (Strayer, 2012, p.172).

\section{Previous Studies into Flipped Learning}

Previously, there have been a substantial number of studies into the application of flipped teaching across various disciplines at universities, namely a biology course (Marrs \& Novak, 2004), a statistics course (Strayer, 2012), a Microsoft Excel course (Davies, Dean, \& Ball, 2013), a course in Actuarial Techniques (Butt, 2014), Pharmacotherapy course (Koo et al., 2016) and marketing research course (Hsieh, Wu, \& Marek, 2017). These researches have generally demonstrated educational values of flipped teaching in improving class preparation, classroom interactivity and academic performance. Nevertheless, research reports in flipped EFL classrooms in higher education settings are not abundant in the literature (Hung, 2015, Webb \& Doman, 2016).

The pioneering research in adopting flipped classroom in EFL context was conducted by Hung (2015), using WebQuest active learning strategy. The findings mirrored most of the previous studies in relation to the effectiveness of flipped classroom in enhancing learners' involvement and participation and promoting outcomes. A notable recent research in flipped learning is the use of LINE smartphone application in teaching English idioms (Hsieh et al., 2017) in comparison with conventional teaching. The results showed flipped instruction with an extensive online interaction motivated learner's participation and enhanced their knowledge. Students in flipped classroom outperformed those in traditional one and were more competent in using learned idioms in communicative interaction activities. Another worth mentioning research is Kim's (2017) about flipped Interpreting classes for postgraduate students. Grounded on CoI framework, this study aimed at exploring students' perceptions and learning experiences in flipped classrooms versus traditional ones. The results echoed findings in previous studies in the sense that flipped learning enhanced students' involvement and collaboration during onsite sessions, improved their performance and noticeably, developed higher-order thinking skills.

Within Vietnamese context, a modest number of studies have been conducted to explore the effectiveness of flipped 
learning such as flipped classroom on Facebook platform for teaching English general (Tran, 2016) and discuss the potential benefits of this learning mode (Bui, 2016; Nguyen, 2014; ; Tran, 2016). A recent research was undertook by Nguyen, Tan, \& Lee (2018) in the same context with this study; i.e. University of Foreign Language Studies, the University of Danang, Vietnam, to examine students' perceptions of obstacles in implementing flipped learning for teaching grammar with the use of qualitative method. However, very few empirical studies into flipped learning in Interpreting courses for undergraduate levels have been found in the existing literature. Hence, this study is designed to explore students' perceptions in flipped Interpreting course and subsequently to make suggestions on pedagogical design. It is hoped that the research outcome would make meaningful contributions to the growing line of flipped teaching and to its successful implementation in Vietnamese EFL teaching and learning context. To address these goals and purposes, this study employed a mixed-method research design with the following guiding questions:

1. How did the students perceive learning experiences in the Flipped Interpreting course?

2. What could be considered in designing and implementing the Flipped Interpreting Course on Moodle Learning Platform?

\section{MEthodology}

\section{A. Participants}

The participants were 37 undergraduate English-majored students, including 5 male and 32 female students aged between 20 and 22 at University of Foreign Language Studies, the University of Danang, Vietnam (see Table 1). They were enrolled in a 10-week Flipped Interpretation course taught by the first author during the first semester of 2018 academic year. All participants were in their third year, which indicated that they had met the mandatory university requirements to achieve an overall English Language Level of B2 on the CEFR-based rating scale (Common European Framework of Reference for Languages). With regard to the previous technology-mediated courses, the minority of participants surveyed (10.8\%) had taken course(s) on Moodle Learning Management Platform, while 21.6\% had prior experiences with the flipped classroom model.

TABLE I.

THE DEMOGRAPHICS OF THE PARTICIPANTS

\begin{tabular}{clll}
\multicolumn{4}{c}{ THE DEMOGRAPHICS OF THE PARTICIPANTS } \\
\hline & & Total & $\%$ \\
\hline Total & Responded & 37 & 100 \\
\hline \multirow{2}{*}{ Gender } & Female & 32 & 86.5 \\
& Male & 5 & 13.5 \\
\hline \multirow{2}{*}{ Age } & 20 & 32 & 86.5 \\
& 21 & 4 & 10.8 \\
\hline Enrolled in courses on Moodle & 22 & 1 & 2.7 \\
Learning Platform before & Nos & 4 & 10.8 \\
\hline Enrolled in Flipped courses & Yes & 33 & 89.2 \\
before & No & 29 & 21.6 \\
\hline
\end{tabular}

\section{B. Instructional Design}

At the beginning of the course, a face-to-face briefing session about online learning platform and course requirements was organized to guarantee that students would have a smooth and easy access to all resources on the platform as well as comprehend all course components and assessment tasks. The researchers chose to adopt Moodle as a Learning Management System (LMS) in the study. From a pedagogical point of view, Moodle offers a less sophisticated and well-structured environment than other commercial LMS due to its availability, versatility and user-friendliness in an active and interactive learning process (Goyal \& Tambe, 2015; Kotzer \& Elran, 2012; Lopes, 2011). Also, in this session, students were randomly divided into smaller groups of four or five for groupwork activities during the course.

In order to facilitate more productive class time, prior to every in-class session, students were requested to use their accounts to log into Moodle to read the assigned chapters, watch the videotaped lectures and PowerPoints with voiceover made by the first author. The online lectures were supplemented with Youtube, TED-Ed videos and other online sources. After watching the video lectures, students then had to engage in the online discussion forum with topic-based discussion prompts, and do short online quizzes. Besides, with an aim of nurturing a positively shared learning culture, a Share2Care corner, which is an optional free-writing activity, was included in the platform so that students felt free to share their reflections about weekly lessons, post any immediate academic or technical queries or problems that they might encounter and receive timely responses and feedback from peers and the instructor.

During the in-class sessions, students were given greater opportunities to engage in a host of student-centered activities. To make sure students were able to understand the content of the pre-recorded video lectures, students in two randomly selected groups were required to do a 15-minute peer teaching at the start of each class. Peer teaching has proven to grow in popularity in educational contexts as it helps students to develop a deeper understanding of the subject matter in a 'purpose-driven and meaningful interaction' (Bradford-watts, 2011). As a follow-up to Peer teaching, Q\&A activity aims to further address any issues in the videos and online Discussion Forum that students might find 
confusing or ambiguous. The majority of the class time was dedicated to more authentic and interactive learning where students applied what they had watched in the video lectures in communicative interpreting tasks. Group-based presentations and interpreting practice were carried out in the form of role-plays, which allowed students to expose themselves to real-life scenario improvisation. These different scenarios given by the instructor varied according to the weekly interpreting themes such as tourism, environment, health, education, to name but a few. Students then received instructor and peer feedback and comments on their groupwork activities.

After face-to-face class meetings, students participate in online interpreting practice on Moodle on an individual basis. Authentic open content in the form of recordings and videos were prepared and uploaded on the LMS by the instructor. Furthermore, students were asked to develop a vocabulary resource by creating theme-based glossary entries on Moodle Glossary tool.

\section{DATA ANALYSIS}

Both quantitative and qualitative methods are employed to gain in-depth information about students' perceptions of the flipped course. A survey questionnaire and individual interviews were conducted to collect data in this study. The entire procedure of instructional design and data collection is briefly summarized in Fig. 1.

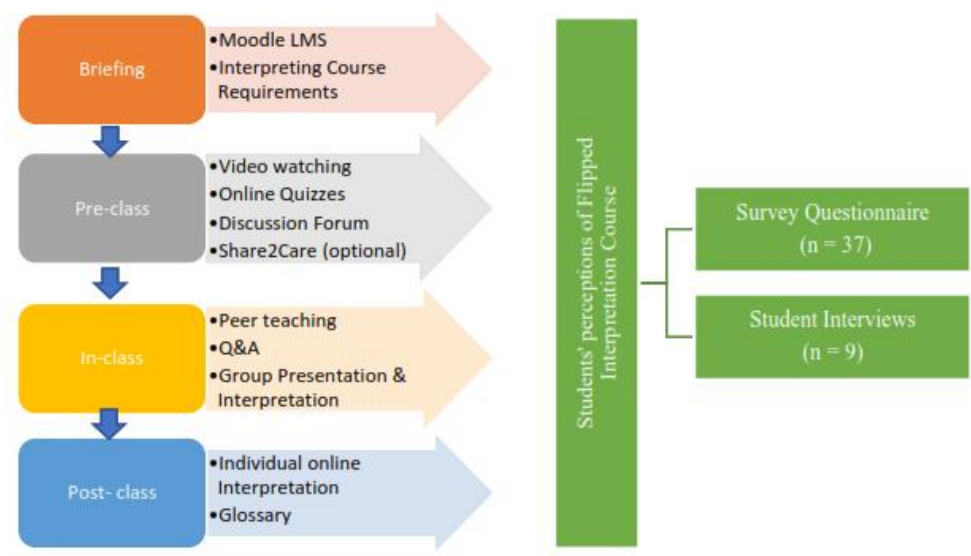

Figure 1: The procedure of the study

\section{A. Quantitative Data}

All 37 participants responded to a 31-item survey questionnaire consisting of four sub-domains. The first three domains including Teaching Presence ( 8 items), Social Presence (6 items), and Cognitive Presence (11 items), were adapted from CoI Instrument by Arbaugh et al. (2008). The last domain, Technology Use (6 items), was added to examine the ease of use and comfort of students when using technologies in the flipped model. The items were designed on a five-point Likert scale, ranging from 1 (strongly disagree) to 5 (strongly agree).

\section{B. Qualitative Data}

As a follow-up to the questionnaire, nine students were invited for an interview in English, which lasted approximately 15 minutes each. The qualitative data were analyzed in order to document the students' experiences about the flipped classroom model in greater depth, as well as propose some implications and suggestions for future design and implementation of the flipped model in Interpretation course.

\section{FINDINGS}

\section{A. Research Question 1: How Did the Students Perceive Learning Experiences in the Flipped Interpreting Course?}

A questionnaire was employed to measure students' overall perceptions in Flipped Interpreting course, which consisted of 31 items. The scale had a high level of internal consistency, as determined by a Cronbach's alpha of 0.913 . The coefficient reliability for each domain was further verified in Table 2.

TABLE II.

\begin{tabular}{ccc}
\multicolumn{3}{c}{ TABLE II. } \\
RELIABILITY OF SURVEY \\
\hline Domain & $\begin{array}{c}\text { Cronbach's } \\
\text { Alpha }(\alpha)\end{array}$ & Nof Items \\
& .766 & 8 \\
TP & .695 & 6 \\
SP & .830 & 11 \\
CP & .845 & 6 \\
TU & & \\
\hline
\end{tabular}


The results also showed a high mean score $(M=4.18)$ for students' overall perceptions of Flipped learning experience as stated in Table 3. This reveals generally positive learning experiences using Flipped instruction in Interpreting Course.

TABLE III.

\begin{tabular}{llllll}
\multicolumn{5}{c}{ DESCRIPTIVE STATISTICS OF STUDENTS' PERCEPTIONS OF FLIPPED CLASSROOM APPROACH } \\
\hline & $N$ & Mean & SD & Min & Max \\
\hline Total & 37 & 4.18 & .40 & 3.03 & 4.77 \\
Valid N (listwise) & 37 & & & & \\
\hline
\end{tabular}

The questionnaire additionally focused on evaluating students' learning experiences in four specific domains, including Teaching Presence, Social Presence, Cognitive Presence and Technology Use. As the results shown in Table 4, participants' responses to all four domains fell into the upper intermediate category.

TABLE IV.

\begin{tabular}{lccccclc}
\multicolumn{8}{c}{ DESCRIPTIVE STATISTICS Of STUDENTS' PERCETIONS OF DOMAINS } \\
\hline Domain & $N$ & Mean & SD & Min & Max & $\begin{array}{l}N \text { of } \\
\text { Items }\end{array}$ \\
\hline TP & 37 & 4.37 & .43 & 3.00 & 4.88 & 8 \\
SP & 37 & 3.95 & .52 & 2.67 & 4.67 & 6 \\
CP & 37 & 4.13 & .47 & 3.00 & 4.82 & 11 \\
TU & 37 & 4.27 & .53 & 3.00 & 5.00 & 6 \\
\hline
\end{tabular}

Among four domains, Teaching Presence topped the rank $(M=4.37)$, indicating that students were highly satisfied with the way the teacher designed, monitored and facilitated the course. Specifically, Item 2 (The instructor provided clear instructions on how to participate in course learning activities) and Item 3 (The instructor clearly communicated important due dates/time frames for the learning activities) had the highest mean scores among all 31 items with $M=$ 4.65 and $M=4.59$ respectively.

The second domain that also yielded productive results was Technology Use $(M=4.27)$. Participants' responses revealed a few difficulties in navigating around, interacting with the teacher and their peers and completing the assignments on Moodle Learning Management System. Particularly, most students shared positive ideas about the easy and convenient access to video lectures and out-of-class materials on Moodle (Item 28, The layout of course content on Moodle site was very clear and user-friendly, with $M=4.38$ ).

Students also had a favourable perception towards Cognitive Presence $(M=4.13)$, noting their ability to gain practical and relevant knowledge in the flipped course and to apply the newly acquired knowledge into performing content-related activities and real-life related tasks in both online and onsite environments. It is notable that Item 26 ( $I$ devoted more time and effort to learning activities in Flipped Classroom than Traditional Classroom) had the lowest mean score $(M=3.84)$ among 11 items in this domain.

With respect to Social Presence, flipped instruction greatly enhanced learners' engagement and interaction by providing a supportive and friendly setting in which students communicated purposefully $(M=3.95)$. Nevertheless, several students raised their concern about the effectiveness of online interactive activities in promoting a sense of trust and collaboration. Item 11 (I felt comfortable disagreeing with other course participants while still maintaining a sense of trust) and Item 12 (I felt that my point of view was acknowledged by other course participants) had the lowest mean scores among 31 items with $M=3.38$ and $M=3.70$ respectively. One student even responded "Strongly Disagree" for these two items.

A semi-structured interview was then conducted to explore students' overall perceptions of flipped classroom approach in greater depth. The data were analyzed for recurring themes, revealing three closely related spheres: (1) motivation, engagement and interaction (2) self-centered learning (3) their perceptions of outcomes.

The most emerging dimension from interviewees' comments was the development of motivation, engagement and interaction. They asserted that flipped instruction on Moodle Learning Management System helped to stimulate their learning interest and led to more participation. One student said, "I had a chance to try an exciting way of learning and I found it pleasing to go to this class. I no longer suffered from complicated theories and count every minute for the break". Another student shared a similar thought, noting, "I haven't tried anything like Moodle before, I find it very fascinating and it gives me inspiration to learn Interpreting Course more effectively". Students also mentioned being more active in class since they needed to do research and explore about the topics before class time and avoiding being a passive knowledge recipient. One student commented, "Being a centered learner makes me more interested in lessons than a normal listener in the traditional class". Most students were particularly impressed with Online Interpretation and Online Discussion sections since these activities on Moodle fostered and enhanced their interaction with the teacher and their peers. One student revealed, "I like Online Interpretation best because of its usefulness. I can freely express my interpretation ability and have opportunities to refer to other students' views". One other student made similar comments about Online Discussion section like "I enjoyed participating in Online Discussion because I could express my opinion without hesitation. I received a lot of feedback from classmates who also participated in Online Discussion, especially the feedback to overcome my weaknesses in doing interpretation". Other students also showed high 
appreciation of Share2Care section where they can share the difficulties in studying and can receive useful feedback from the teacher and advice from their classmates. "This section is a good communication tool between teacher and students and it helps me to go through difficulties I encounter", one student remarked.

The second theme in student analysis was that flipped Interpreting course in this study was a novel and useful way to promote learners' self-centered learning. Most students reported that they could watch lecture videos as many times as they wished for pre-class preparation and could have direct and constant access to lessons' contents and materials. One student said, "I can watch the videos many times and thoroughly understand to prepare the lessons well before coming to class". Another had a similar thought, commenting, "I am able to learn all the theories every time and everywhere I want". Participants additionally stressed greater opportunities they had for interpreting practice during on-site session compared with that in conventional classroom. "I have more time to practice with teacher and do teamwork exercises in class which I find very useful", noted one student. One student emphasized the greater level of autonomous learning that he/she had when learning on Moodle and said, "Learning on Moodle is a modern method that helps me more creative and promote my self-study".

Finally, respondents also analysed their experiences in this study in terms of their perceptions of outcomes. Most students witnessed an improvement not only in their interpreting but also listening skills throughout the course. Moreover, they absorbed more useful and relevant knowledge, not only the one in textbooks and actively expressed their viewpoints. One student concluded, "I explore topics in greater depth and this course created meaningful learning opportunities and I can understand lessons clearly and thoroughly".

\section{B. Research Question 2: What Could Be Considered in Designing and Implementing the Flipped Interpreting Course on Moodle Learning Platform?}

The associations among the four domains including TP, SP, CP and TU were investigated using Pearson productmoment correlation coefficient (see Table 5). Preliminary analyses were performed to ensure no violation of assumptions of normal distribution and linearity.

TABLE V.

CORRELATIONS AMONG THE FOUR DOMAINS

\begin{tabular}{|c|c|c|c|c|}
\hline & 1 & 2 & 3 & 4 \\
\hline 1. TP & - & $.462^{* * *}$ & $.568^{* *}$ & $.401^{*}$ \\
\hline 2. SP & - & -- & $.754^{* *}$ & $.596^{* *}$ \\
\hline 3. $\mathrm{CP}$ & & & -- & $.561^{* *}$ \\
\hline 4. TU & & & & -- \\
\hline
\end{tabular}

The figures in Table 5 show significant, positive correlation values, ranging from 0.401 to 0.754 . On the basis of the guidelines on the strength of relationships suggested by Cohen (1988), a strong correlation was identified in the relationships of SP-CP, TP-CP, TU-CP with $r=0.754,0.568$, and 0.561 respectively. Meanwhile the analysis showed medium correlation values of TP-SP $(r=0.462, p<0.01)$ and TP-TU $(r=0.401, p<0.05)$.

The correlations among the four key variables are represented in Fig. 2 with strong correlation values of over 0.5 in solid lines, and medium correlation values of 0.4 in dashed lines. Noticeably, CP, being at the center of the relationship, were found to strongly correlate with all other domains. This indicates that students tend to reap substantial benefits in learning and constructing deep and meaningful knowledge when this process is implemented in a dynamic interconnection with other domains.

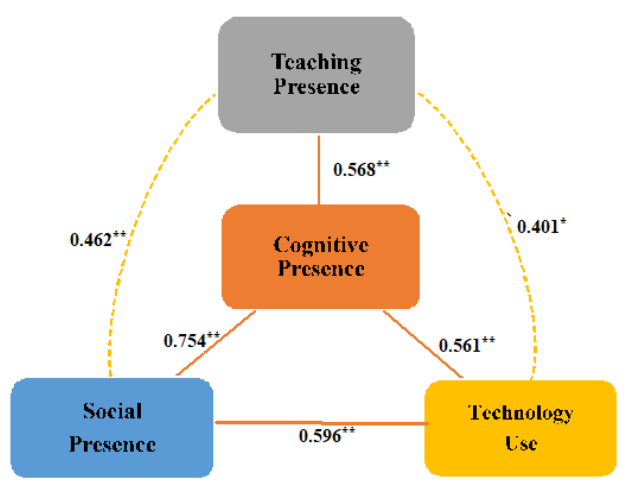

Figure 2: The correlation values among the domains

The highest correlation value was found in SP-CP $(r=0.754, p<0.01)$. Student perceived that a purposeful and collaborative learning environment has a significant influence on their deep learning experiences. This is confirmed by the students' responses in the interview. One student responded, "I made the most of online interpreting activities, where I could take notes of the ideas and good interpreting versions that my classmates shared to minimize my weaknesses and improve my own interpreting work". Other students explained, "I could interact more with my friends 
to improve my interpretation skills', "I loved to prepare lessons and home tasks in advance so that I could share what I've learnt to other students". Besides, Discussion Forum activity, which profoundly facilitates social presence, was highly favoured by students in stimulating them to express ideas about the given topics, post comments and receive a lot of peer feedback to consolidate their knowledge and skills in interpretation.

Furthermore, there was a significant, strong correlation between SP and TU $(r=0.596, p<0.01)$. The responses from the interview demonstrated a high concensus among students about the adoption of Moodle learning platform in promoting collaborative learning. All respondents agreed that Moodle turned out to be a helpful interaction and communication tool for students and should be adopted in future courses. Besides, Fig. 2 indicates a strong correlation between TP-CP, TU-CP with $r=0.568$ and 0.561 respectively. Undeniably, continuous teacher guidance and technolgy support directly foster students' engagement, active learning and autonomy in realizing ultimate learning outcomes.

Interestingly, with lower values of 0.462 and 0.401 , there were medium correlations in TP-SP and TP-TU. Although quantitative data from the questionnaire show a high mean score of $\mathrm{TP}, \mathrm{SP}$, and $\mathrm{TU}, M=4.37,3.95$, and 4.27 respectively (see Table 4), students' comments in the interview revealed that they sometimes had difficulties when studying on Moodle platform. One student commented, "I found a bit confusing to explore Moodle, although the activities and content are well-organized. Some tools and their functions on Moodle are not clear enough for students to make the most of them". Time management is another problem for students when using Moodle. Two other students added, "I could not manage the time when using Moodle", "It is hard for me to meet the deadlines. I could not remember the due date of the assignments". This implies that teachers should take due considerations of careful design and detailed instruction in making sure students can fully engage themselves in an effective collaborative community and trouble-free use of technology in a flipped course.

\section{DisCUSSIONS}

\section{A. Students' Overall Perceptions in Flipped Interpreting Course}

The primary finding of this study was students' high appreciation of flipped instructional design in the Interpreting course. They showed positive perceptions of every examined domain, namely Teaching Presence, Social Presence, Cognitive Presence and Technology Use, thus validating the benefits of flipped instruction in language learning in general and in Interpreting courses in particular. This research outcome aligns with previous studies that have also shown positive results in students' attitudes as well as their academic performance in flipped classrooms (Hsieh et al., 2017; Kim, 2017; Quyen, 2017).

Teaching Presence had the highest level of satisfaction among participants. Regarding aspect of instructional management, students were highly appreciative of the way the teacher designed, implemented and monitored the course. They were particularly satisfied with the teacher's clear instructions and communication in relation to due dates and time frames of the course. In terms of building understanding, most students realized that the teacher spent a great deal of time and effort in keeping students engaged via a variety of both in-class and out-of-class activities. In view of direct instruction, most participants appreciated the teacher's new roles in flipped classroom as a moderator and facilitator, rather than a lecturer. The teacher provided necessary guidance, explanations and timely feedback. Some students revealed in the interview that they significantly benefited from teacher's feedback and comments and this practice helped to maximize student-centered learning and stimulate learners' motivation. This is consistent with the study by Sarawagi (2014) in that instructors in flipped classroom serving as a guide would allow students to improve engagement and learn actively.

Although Social Presence did not receive as high satisfaction as the other domains, students generally had positive perceptions towards this category. Most students affirmed the benefits of flipped model in promoting positive emotions, including enjoyment and an increase of motivation as stated in the interview. This course also helped to improve their interaction with the teacher and their peers as well as develop their sense of collaboration. Particularly, they found interactive sections, namely Online Interpretation, Online Discussion and Share2care section fascinating and beneficial. This outcome is incompatible with Li, Zhang, Bonk \& Guol (2015) and Quyen (2017), which revealed students' dissatisfaction with interaction in flipped classroom. This is also in contradiction to Kim's (2017) in that students claimed that online discussions in flipped classroom did not improve their sense of collaboration. Nevertheless, some students felt that they were not comfortable disagreeing with other course participants when still maintaining a sense of trust and their viewpoints were not appropriately acknowledged. This was related to mutual awareness and recognition as stated by Garrison et al (2000). Students' relationships in online environment were sustained through their reply to post messages, their comments or their explicit referring to others' posts. Furthermore, explicit appreciation, complimenting, encouragement are necessary for online students to feel recognized. From observation, these components were missing in the online interaction in this study. The plausible reasons are students had to fulfil the requirements of many different courses in a semester, which might have led to their lack of engagement in the online sessions. Additionally, the teacher could not closely monitor online interaction of students since she had to prepare videos and instructional materials and condense course content to prepare students for the end-of-semester examination.

In view of Cognitive Presence, students claimed that they could explore and understand new useful theoretical concepts in Interpretation via watching videos and lectures for pre-class preparation. They also had opportunities to 
reflect on the acquired knowledge through peer-teaching and other onsite practice activities. Moreover, they could apply acquired knowledge into resolving relevant and practical issues in class and in real life. This is harmonious with Kim's (2017) in that flipped instruction helped to develop practical solutions and application skills for students. Of notable interest in this study is that students appreciated the time and effort they spent in pre-class preparation and practice in this flipped Interpreting course and did not agree that they had to spend too much time and effort on learning activities compared with traditional classroom. This is different from the situation in Hsieh et al (2017) in which students complained that they had a greater workload and time commitments in flipped classroom. The convincing reason could be that learners in this research were aware that the time in flipped learning was of higher quality than that in conventional instructional classes (Rahman \& Mohamed, 2014) since they could develop their learning autonomy via student-centered learning activities, which consequently led to their sense of achievement and their development in Interpreting skills as supported by interview data. In other words, the benefits were perceived to lie in fruitful quality of time the students gained, rather than the large quantity of time they must devote.

Finally, participants had positive perceptions towards the use of Moodle Learning Management System in this Flipped Interpreting course. Most of them agreed that Moodle was user-friendly and provided a stimulating and effective learning environment, which enhanced interaction and collaboration. Nevertheless, minor improvements should be made about the sound quality of videos uploaded onto Moodle in this study.

\section{B. Considerations in Designing and Implementing the Flipped Interpreting Course on Moodle Learning Platform}

Flipped classroom model brings about both affordances and challenges for students, thereby requiring proper considerations in the design and implementation of the course. This section discusses the dynamic interconnection of four domains (TP, CP, SP and TU) and puts forward some proposals for running an effective flipped course.

Build up a collaborative community of learners to enhance cognitive development

It is not surprising that the correlation between SP and CP reached a positive high value in this study. In fact, students' perceptions showed that establishing a purposeful and collaborative environment is a key element that fosters their cognitive development and critical thinking. An opportunity to negotiate meaning, concepts and tasks with other learners socially and emotionally allows students to engage themselves in deep learning via a process of questioning, reasoning, connecting, deliberating, challenging, and developing problem-solving techniques (Lipman, 1991). This finding agrees with Garrison et al (2000) who contended that a high level of socio-emotional interaction is accompanied with a high degree of cognitive development in attaining educational outcomes. The evidence supporting the strong interconnection between these two domains is growing in the body of research (Ramsden, 1988; Resnick, 1991; Molinari, 2004; Beuchot \& Bullen, 2005; Celani, \& Collins, 2005). Therefore, it is necessary for teachers to develop a greater sense of interactive community with well -designed tasks for students. Some prevailing on-site activities include teamwork tasks that urge students to support each other or assessment activities that focuses on the ability to evaluate peers' performance. Regarding online activities specifically on Moodle Learning Platform, teachers can make the most of such available tools as Forum (for asynchronous discussion), Workshop (for online peer evaluation and feedback), and Chat (for a real-time synchronous discussion).

Integrate easy and friendly use of Technology in the learning process

In this digital age, the delivery of information should not be confined in the traditional approaches. Students, therefore, need contant access to the readily-available technological tools to personalize their learning and accommodate their learning needs. The findings in this study demonstrate students' high appreciations of Moodle Learning Management Platform in providing them an effective tool that entailed high interaction and interpreting skill improvement. In fact, the use of technology has been proven in the academic literature to be beneficial in enhancing social and cognitive elements (McGrath et al, 2017; Alavi et al, 2002; Murphy, DePasquale, \& McNamara, 2003). Accordingly, it is essential for students in the flipped classrooms to be exposed to technologies to make the most of their learning experiences. However, considerations in terms of student digital literacy skills, the availability of technological tools, flexibility in time, pace of learning, and delivery modes (computer or mobile access) should be all taken into account so that technology should become an aid, not a barrier to the learning process.

Provide constant feedback and sufficient scaffolding for students

It is noteworthy in this study that the relationships among TP-TU and TP-SP was found to have the lowest correlation values compared to other correlations (see Table 5). Despite an overall positive perceptions of students toward the use of technologies during the course, several of them encountered some problems in terms of time management and Moodle-based tool navigation, apart from the sound quality of video lectures as revealed in the interview. This can be due to the fact that only a minority of students had previous experiences with Moodle (see Table 1). First exposure to a new learning platform might confuse students and hinder them from fully exploiting the tools to complete the assigned tasks. This finding is in coherence with studies by McGrath et al., (2017), Goossens, Jefferies, \& Bullen (2008), and Kennedy et al (2010). Consequently, the researchers concluded that instructors in the flipped classes should not only consider careful design on online learning platform but also provide detailed guidance and instruction on how to access the technologies at ease. Teachers also need to be present to provide timely scaffolding, both online and onsite, to guarantee the students are free from technological troubles.

Besides, with regard to the CoI framework, growing studies in the field have shown that students' perceptions of teaching presence strongly influence those of social presence and cognitive presence (Garrison et al., 2000; Shea, Li, 
Swan, \& Pickett, 2005; Akyol \& Garrison, 2008; Garrison et al, 2010). What these studies revealed is that teaching presence becomes a determinant of students' deep learning and a sense of community. As a result, a well-designed course and sufficient direction and support from the teachers are necessary to enable an effective flipped course. This was confirmed by Garrison et al. (2000) who pointed out two main functions of teaching presence. The first function refers to "the design of educational experience which includes the selection, organization, and primary presentation of course content, as well as the design and development of learning activities and assessment" (p.90). The second function is defined by "facilitation", which is a responsibility of the teacher to sustain a collaborative community of learners to share meanings and understanding.

\section{CONCLUSION}

The results of the study revealed that flipped instruction in the Interpreting course generated positive perceptions among students. Particularly, students were highly satisfied with the teacher's emerging role as a moderator and facilitator. Learners had more opportunities to develop self-centered learning, engage actively and collaborate effectively in a community of learning. Importantly, they perceived their abilities to critically apply knowledge into their real-life tasks, which ultimately helped them to achieve more satisfying outcomes. The study also proved the beneficial affordances of Moodle as an effective platform for running flipped courses.

The study additionally offers some recommendations for practice.

(1) A strong correlation between SP and CP should be maintained to enhance learners' cognitive development through collaborative learning activities and well-orchestrated tasks.

(2) When using flipped instruction, teacher's presence is vital to provide useful scaffolding and to intervene when necessary to help students flourish in the learning community.

(3) Students need to be properly trained regarding the use of instructional technology so that they could get themselves well acquainted with these tools. This would enhance their learning experiences and yield beneficial outcomes. Continuous technological support is also important; however; this might require more time and commitment from the teacher or instructor.

\section{REFERENCES}

[1] Alavi, M., Marakas, G. M., \& Yoo, Y. (2002). A Comparative study of distributed learning environments on learning outcomes. Information Systems Research, 13, 404-415.

[2] Akyol, Z., \& Garrison, D. R. (2008). The development of a community of inquiry over time in an online course: Understanding the progression and integration of social, cognitive and teaching presence. Journal of Asynchronous Learning Networks, 12(3), $3-22$.

[3] Akyol, Z., Garrison, D. R., \& Ozden, M. (2009). Online and Blended Community of Inquiry: Exploring the Developmental and Perceptual Differences. The International Review of Research in Open and Distance Learning, 10(6), 68-53.

[4] Arbaugh, J. B., Cleveland-Innes, M., Diaz, S. R., Garrison, D. R., Ice, P., Richardson, J. C., \& Swan, K. P. (2008). Developing a community of inquiry instrument: Testing a measure of the Community of Inquiry framework using a multi-institutional sample. Internet and Higher Education, 11(3-4), 133-136. https://doi.org/10.1016/j.iheduc.2008.06.003.

[5] Baepler, P., Walker, J., \& Drissen, M. (2014). It's not about seat time: Blending, flipping, and efficiency in active learning classrooms. Computers \& Education, 78, 227-236.

[6] Beuchot, A., \& Bullen, M. (2005). Interaction and interpersonality in online discussion forums. Distance Education, 26(1), 6787.

[7] Bishop, J., \& Verleger, M. A. (2013). The Flipped Classroom: A survey of the research. In 2013 ASEE Annual Conference \& Exposition. Atlanta, Georgia.

[8] Boxser, M. (2015). Has technology been good for education? https://www.weforum.org/agenda/2015/04/has-technology-beengood-for-education/ (accessed 5/5/2019).

[9] Bradford-watts, K. (2011). Students teaching students? Peer teaching in the EFL classroom in Japan. The Language Teacher, 35(5), 31-36.

[10] Bui, T. M. T. (2016). Applying flipped learning in the Vietnamese EFL context: A theoretical discussion of the benefits and challenges. Journal of Military Foreign Language Studies, 3, 33-37.

[11] Butt, A. (2014). Student Views on the use of Classroom Approach: Evidence from Australia. Business Education and Accreditation, 6(1), 33-44.

[12] Celani, M. A. A., \& Collins, H. (2005). Critical thinking in reflective sessions and in online interactions. AILA Review, 18, 4157.

[13] Cohen, J. (1988). Statistical Power Analysis for the Behavioral Sciences (2nd ed.). Hillsdale, NJ: Lawrence Erlbaum Associates.

[14] Davies, R., Dean, D., \& Ball, N. (2013). Flipping the classroom and instructional technology integration in a college-level information systems spreadsheet course. Educational Technology Research and Development, 61(4), 563-580.

[15] Dill, E. (2012). The impact of flip teaching on student homework completion, behaviour, engagement and proficiency. Armidale: University of New England.

[16] Fisher, D., Frey, N., \& Hite, S. A. (2016). Intentional and Targeted Teaching: A Framework for Teacher Growth and Leadership. Alexandria, VA USA: ASDC.

[17] Garrison, D. R., Anderson, T., \& Archer, W. (2000). Critical inquiry in a text-based environment: Computer conferencing in higher education. The Internet and Higher Education, 2, 87-105.

[18] Garrison, D. R., Cleveland-Innes, M., \& Fung, T. S. (2010). Exploring causal relationships among teaching, cognitive and 
social presence: Student perceptions of the community of inquiry framework. Internet and Higher Education, 13(1-2), 31-36. https://doi.org/10.1016/j.iheduc.2009.10.002.

[19] Garrison, D. R., \& Vaughan, N. (2008). Blended learning in higher education: Framework, principles and guidelines. San Francisco, CA: Jossey-Bass.

[20] Goossens, Y., Jefferies, A., \& Bullen, P. (2008). Technology at University: New Students' Expectations for Social and Academic Uses. World Conference on Educational Multimedia, Hypermedia and Telecommunications.

[21] Goyal, E., \& Tambe, S. (2015). Effectiveness of Moodle-Enabled Blended Learning in Private Indian Business School Teaching Niche. The Online Journal of New Horizons in Education, 5(2), 14-22.

[22] Hsieh, J. S., Wu, W., \& Marek, M. (2017). Using the flipped classroom to enhance EFL learning. Computer Assisted Language Learning, 30(1-2), 1-21. https://doi.org/https://doi.org/10.1080/09588221.2015.1111910.

[23] Hsieh, J. S. C., Wu, W.-C. V., \& Marek, M. W. (2017). Using the flipped classroom to enhance EFL learning. Computer Assisted Language Learning, 30(1-2), 1-21. https://doi.org/10.1080/09588221.2015.1111910.

[24] Hung, H.-T. (2015). Flipping the classroom for English language learners to foster active learning. Computer Assisted Language Learning, 28(1), 81-96.

[25] Kennedy, G., Judd, T., Dalgarno, B., \& Waycott, J. (2010). Beyond natives and immigrants: Exploring types of net generation students. Journal of Computer Assisted Learning, 26(5), 332-343.

[26] Kim, D. (2017). Flipped interpreting classroom flipping approaches student perceptions.pdf. The Interpreter and Translator Trainer, 11(1), 38-55. https://doi.org/https://doi.org/10.1080/1750399X.2016.1198180.

[27] Kim, M., Kim, S., Khera, O., \& Getman, J. (2014). The experience of three flipped classrooms in an urban university: An exploration of design principles. The Internet and Higher Education, 22, 37-50.

[28] Kong, S. (2014). Developing information literacy and critical thinking skills through domain knowledge learning in digital classroom: An experience of practicing flipped classroom strategy. Computers \& Education, 78, 160-173. https://doi.org/https://doi.org/10.1016/j.compedu.2014.05.009.

[29] Koo, C. L., Demps, E. L., Farris, C., Bowman, J. D., Panahi, L., \& Boyle, P. (2016). Impact of Flipped Classroom Design on Student Performance and Perceptions in a Pharmacotherapy Course. American Journal of Pharmaceutical Education, 80(2), 19.

[30] Kotzer, S., Elran, Y. (2012). Learning and teaching with Moodle-based E-learning environments, combining learning skills and content in the fields of Math and Science \& Technology. 1st Moodle Research Conference, 122-131.

[31] Li, Y., Zhang, M., Bonk, C., \& Guol, N. (2015). Integrating MOOC and Flipped Classroom Practice in a Traditional Undergraduate Course: Students' Experience and Perceptions. IJET Journal, 10(6), 4-10.

[32] Lipman, M. (1991). Thinking in Education. Cambridge: Cambridge University Press.

[33] Lopes, A. P. (2011). Teaching with Moodle in Higher Educations: Polytechnic Institute of Oporto - IPP. INTED2011 Proceedings, 970-976.

[34] Marrs, K., \& Novak, G. (2004). Just-in-time teaching in biology: creating an active learner classroom using the Internet. Cell Biology Education, 3(1), 49-61.

[35] McGrath, D., Groessler, A., Fink, E., Reidsema, C., \& Kavanagh, L. (2017). Technology in the Flipped classroom. In C. Reidsema, L. Kavanagh, R. Hadgraft, \& N. Smith (Eds.), The Flipped Classroom Practice and Practices in Higher Education. Singapore: Springer Singapore : Imprint: Springer, 37-56.

[36] Mc Laughlin, J., Roth, M., Glatt, D., Gharkholonarche, N., Davidson, C., Griffin, L., \& Mumper, R. (2014). The flipped classroom: A course redesign to foster learning and engagement in a health professions school. Academic Medicine, 89(2), 236-243.

[37] Molinari, D. L. (2004). The role of social comments in problem-solving groups in an online class. American Journal of Distance Education, 18(2), 89-101.

[38] Moravec, N., Williams, A., Aguilar-Roca, N., \& O’Dowd, D. (2010). Learn before lecture: A strategy that improves learning outcomes in a large introductory biology class. CBE-Life Sciences Education, 9(4), 473-481.

[39] Murphy, K. L., DePasquale, R., \& McNamara, E. (2003). Meaning connections: using technology in primary classrooms. Young Children on the Web, 58(6), 1-9.

[40] Nguyen, H. A. V., Tan, C. K., \& Lee, K. W. (2018). Students' Perceived Challenges of Attending a Flipped EFL Classroom in Viet Nam. Theory and Practice in Language Studies, 8(11), 1504. https://doi.org/10.17507/tpls.0811.16.

[41] Nguyen, V. L. (2014). The flipped classroom: A model of blended learning. Science Journal - Can Tho University, 34, 56-61.

[42] Quyen, T. T. T. (2017). Students' perceptions of flipped model on Facebook for educational purposes. IOSR Journal of Research \& Method in Education (IOSR-JRME), 7(3), 7-14. https://doi.org/10.9790/7388-0703020714.

[43] Rahman, A., \& Mohamed, H. (2014). The influences of flipped classroom: A meta analysis approach every student capability in every class. In Paper presented at the IEEE 6th International Conference on Engineering Education, Kuala Lumpur.

[44] Ramsden, P. (1988). Improving learning: New perspectives. London: Kogan Page.

[45] Resnick, L. B. (1991). Shared cognition: Thinking as social practice. In L. B. Resnick, J. M. Levine, \& S. D. Teasley (Eds.), Perspectives on socially shared cognition. Washington, DC: American Psychological Association, 1-20.

[46] Sarawagi, N. (2014). A flipped CS0 classroom: Applying Bloom's taxonomy to algorithmic thinking. Journal of Computing Sciences in Colleges, 29(6), 21-28.

[47] Shea, P., \& Bidjerano, T. (2013). Understanding Distinctions in Learning in Hybrid, and Online Environments: An Empirical Investigation of the Community of Inquiry Framework. Interactive Learning Environments, 21(4), 355-370. https://doi.org/10.1080/10494820.2011.584320.

[48] Shea, P., Hayes, S., Smith, S., Vickers, J., Bidjerano, T., Alexandra, P., Jian, S. (2012). Learning Presence: Additional research on a new conceptual element within the Community of Inquiry (CoI) Framework. The Internet and Higher Education, 15, 8995. https://doi.org/10.1016/j.iheduc.2011.08.002.

[49] Shea, P., Li, C., Swan, K., \& Pickett, A. (2005). Developing learning community in online asynchronous college courses: The role of teaching presence. Journal of Asynchronous Learning Networks, 9(4), 59-82. 
[50] Strayer, J. (2012). How learning in an inverted classroom influences cooperation, innovation and task orientations. Learning Environments Research, 15(2), 171-193.

[51] Tran, T. (2016). Applying the "flipped classroom model" for teaching a foreign language. Journal of Foreign Language Studies, Ha Noi University, 46, 67-72.

[52] Tucker, B. (2012). The flipped classroom. Education Next, 12(1), 82-83.

[53] Webb, M., \& Doman, E. (2016). Does the flipped classroom lead to increased gains on learning outcomes in ESL/EFL contexts? CATESOL Journal, 28(1), 39-67.

[54] Zappe, S., Leicht, R., Messner, J., Litzinger, T., \& Lee, H. W. (2009). Flipping the classroom to explore active learning in a large undergraduate course. In Paper presented at 2009 Annual Conference \& Exposition. Austin, TX. Retrieved from https://peer.asee.org/454 (accessed 10/5/2019).

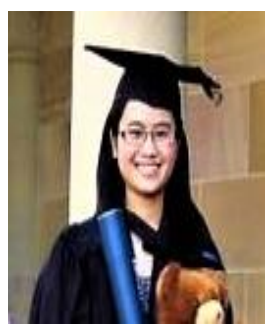

Thi Lan Huynh is currently a lecturer of English at the University of Foreign Language Studies, the University of Danang, Vietnam. She obtained an M.A. in Applied Linguistics in 2011 at the University of Queensland, Australia. She continued to pursue her professional development programs in the Netherlands in 2014 and Australia in 2018. Her major areas of interest include English teaching methodology, CALL, and Translation and Interpretation.

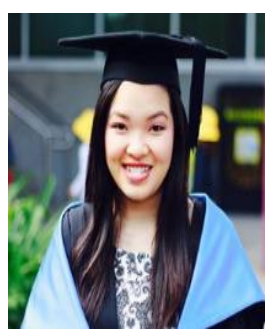

Uyen Nu Thuy Nguyen is a lecturer of English at the University of Foreign Language Studies, the University of Danang, Vietnam. She obtained an M.A. in Applied Linguistics in 2013 at the University of Queensland, Australia. She is currently doing PhD degree at the University of Tasmania, Australia. Her major areas of interest include English teaching methodology, online education and CALL. 